\title{
Občutljivost sort evrojaponskega kostanja (Castanea sativa x Castanea crenata) na kostanjev rak (Cryphonectria parasitica), ambrozijskega podlubnika (Xylosandrus germanus) in kostanjevo šiškarico (Dryo- cosmus kuriphilus)
}

\author{
Maja JURC ${ }^{*}$, Matej REŠČIČ ${ }^{2}$
}

Evropski pravi kostanj (Castanea sativa Mill.) in njegovi križanci (npr. sorte evrojaponskega kostanja $C$. sativa x C. crenata) postajajo v zaostrenih ekonomskih in ekoloških razmerah vse bolj pomembni. Od leta 2002 so v sortni izbor za Slovenijo uvrščene štiri perspektivne sorte evrojaponskega kostanja (»Marsol«, »Maraval«, »Bouche de Bétizac«, »Precoce migoule«), leta 2007 so dodali še dve sorti: »Sobota« in »Garronerosso« (Godec in sod., 2003). O pomenu kostanja pričajo, med drugim dejavnostmi, tudi številni kongresi, ki se v zadnjih letih kar vrstijo in na njih obravnavajo ekonomski pomen lesa, plodov, medu in drugih proizvodov iz evropskega pravega kostanja in njegovih križancev, njihov pomen kot gradnikov gozdov, njihovo ekologijo, drevesničarsko proizvodnjo, hibridizacijo, varstveno problematiko, ter njihove etnološko-kulturne vidike ( $1^{\text {st }}$ European Congress on Chestnut 2009, Italija, $5^{\text {th }}$ International congress on chestnut 2012, Shepherdstown, West Virginia, USA; $2^{\text {nd }}$ European Congress on Chestnut, Debrecen, Madžarska, 2013, načrtujejo pa organizacijo šestega mednarodnega kongresa na to tematiko leta 2016 v Turčiji in tretjega evropskega kongresa leta 2016). Udeležili smo se letošnjega evropskega kongresa na Madžarskem in se seznanili z novostmi na tem področju. Poročali so o številnih raziskavah v zvezi z odpornostjo C. sativa in njegovih križancev na škodljivce in bolezni. Tudi iz naše prakse lahko navedemo nekaj zanimivih opažanj, ki so nastala kot rezultat nenačrtovanega poskusa, vendar so pridobljeni rezultati pomembni v pisanem mozaiku znanja o tej drevesni vrsti.

S sortami evrojaponskega kostanja $C$. sativa x $C$. crenata so se začeli naši gozdarji poskusno ukvarjati leta 2006 , ko so na delu parcele št. 472/10 in na parceli št. 472/11, k.o. Stara Gora, odd/ods 57, GGE Gorica, na približno 0,5 ha veliko kmetijsko površino zasadili 89 triletnih sadik evrojaponskega kostanja, in sicer sorte »Bouche de Bétizac« (52 sadik), »Maraval« (19 sadik) in »Marsol« (18 sadik) (Slika 1, 2). Prvo leto so se sadike uspešno prijele, z leti pa so se začele množično pojavljati okužbe s kostanjevim rakom (Cryphonectria parasitica /Murrill/ Barr), in je nekaj sadik odmrlo. Najobčutljivejša je bila sorta »Bouche de Bétizac«. Do spomladi leta 2010, ko so bila drevesa stara 7 let, je preživelo 34 drevesc sorte »Bouche de Bétizac« (65 $\%), 16$ drevesc sorte »Maraval« (84\%) in 15 drevesc sorte »Marsol« $(83 \%)$. V sredini aprila 2010 je bil zabeležen napad ambrozijskega podlubnika Xylosandrus germanus (Blandfort, 1894) in sicer od cepljenega mesta do višine $1.3 \mathrm{~m}$. Napad so poskušali omiliti z doma pripravljenimi lovnimi vabami (alkoholne vabe $\mathrm{z}$ lepljivimi ploščami), vendar so imele lovne vabe slab učinek. Ugotovljeno je bilo, da so podlubniki napadli
29 dreves sorte »Bouche de Bétizac« $(85 \%), 6$ dreves sorte »Maraval« $(38 \%)$ in 2 drevesi sorte »Marsol« (13 $\%$ ). Uničenje odmrlih dreves in panjev s kurjenjem so izvedli 26.05.2010. Do jeseni 2010 pa so se na vseh drevesih pojavili izraziti simptomi okužbe s kostanjevim rakom. Od skupaj 38 posekanih dreves so osem dreves $(25 \%)$ posekali na panj, ker so ta drevesa kazala dobre znake odganjanja iz panjev, vendar je nasad kmalu dokončno propadel. Izkazalo se je torej, da so vse sorte evroazijskega kostanja, ki so bile uporabljene v poskusu, občutljive na kostanjev rak in ambrozijskega podlubnika, sorta »Bouche de Bétizac« pa je na kostanjevega raka in podlubnika po izkušnjah do leta 2010 najmanj odporna.

Od leta 2004 je pri nas prisotna tudi invazivna kostanjeva šiškarica (Dryocosmus kuriphilus Yasumatsu, 1951), ki se hitro širi v sestojih z evropskim pravim kostanjem. Na kongresu na Madžarskem so italijanski strokovnjaki poročali o relativni rezistentnosti sorte »Bouche de Bétizac« na napade D. kuriphilus in so priporočali povečanje uporabe te sorte (Dini in sod., 2013). Glede na rezultate predstavljenih opazovanj je potrebno obravnavati varstveno problematiko evropskega pravega kostanja in njegovih križancev (sort) celostno in upoštevati občutljivost na škodljive biotske dejavnike (Slika 3a, 3b, 4).

Veliko je bilo govora tudi o vnosu naravnega sovražnika D. kuriphilus, Torymus sinensis Kamijo, 1982 v nove ekosisteme $\mathrm{z}$ namenom biotičnega zatiranja kostanejve šiškarice (primeri iz Italije in najnovejši primer iz Francija) (Quacchia in sod., 2013). Izkušnje številnih raziskovalcev potrjujejo dejstvo, da se na kostanjevo šiškarico v novem okolju relativno hitro naselijo domači parazitoidi, ki večinoma parazitirajo ose šiškarice na hrastih (Jurc in sod., 2013). Zmanjševanje velikosti populacije $D$. kuriphilus z njegovimi naravnimi domačimi sovražniki (parazitoidi) je edini sprejemljiv način biotičnega zatiranja kostanjeve šiškarice, ki že poteka v naših gozdovih.

\section{Viri}

Dini F., Sartor C., Torello Marinoni D., Botta R., 2013. Chestnut transcriptome NG sequencing: a naw tool to investigate gall wasp response. V: Book of abstracts : Debrecen, Baia Mare, Modry Kamne, 9.-12. 10. 2013

Godec B., Hudina M., Ileršič J., Koran D., Solar A., Usenik V., Vesel V. 2003. Kostanj- evropski križanci (Castanea sativa x Castanea crenata). V: Sadni izbor za Slovenijo 2002. Krško, Revija za sadjarstvo, vinogradništvo in vrtnarstvo: 126-127

Jurc M., Mihajlović L., Fernández, M.F., Borkovič D., 2013. Differences in occurrence of Dryocosmus kuriphilus parasitoids depend on time of chestnut gall wasp introduction to Slovenia and Spain. V: Book of abstracts: Debrecen, Baia Mare, Modry Kamne, 9.-12. 10. 2013 
Quacchia A., Askew R.R., Moriya S., Schönrogge K., 2013. Torymus sinensis: biology, host range and hybridization. V: Book of abstracts: Debrecen, Baia Mare, Modry Kamne, 9.-12. 10. 2013

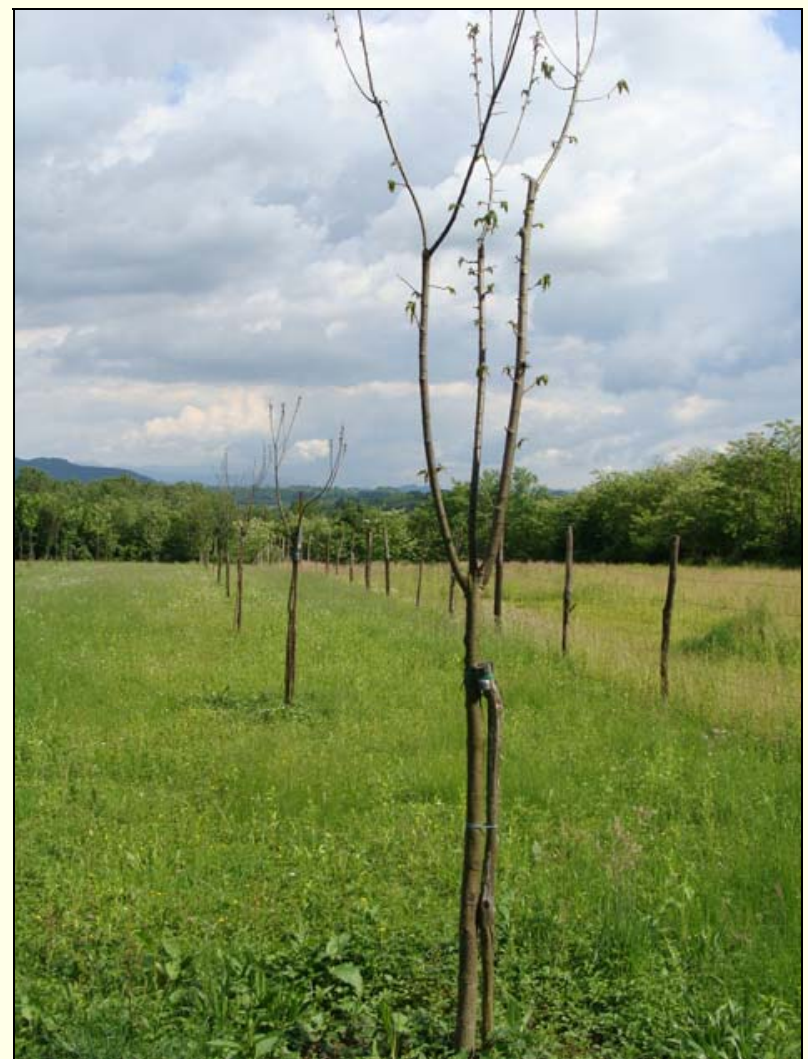

Slika 1: Leta 2006 zasnovan nasad evrojaponskega kostanja (sorte »Bouche de Bétizac«, »Maraval« in »Marsol«) (Foto: M. Reščič)

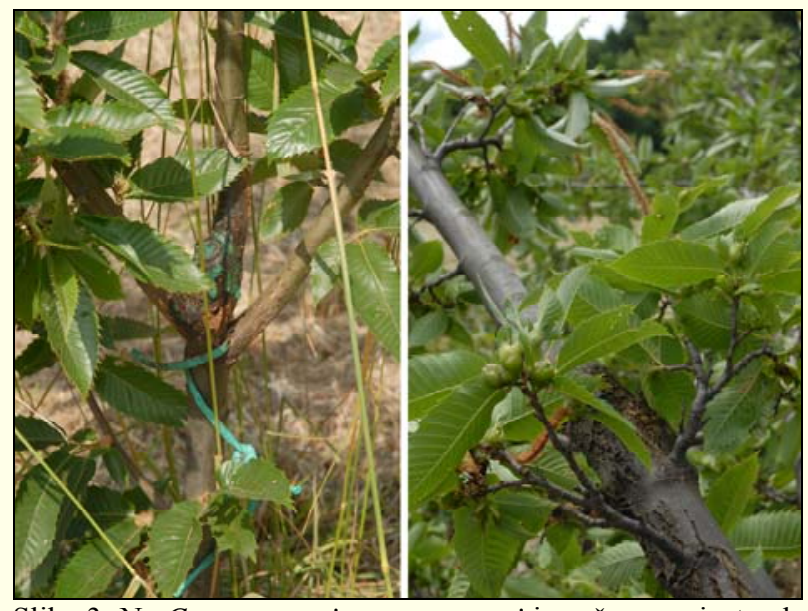

Slika 3: Na Castanea sativa var. maroni je sočasno prisoten kostanjev rak in kostanjeva šiškarica, slikano v bližini Sabotina, 29.6.2007 (Foto: M. Jurc)
1 Univerza v Ljubljani, Biotehniška fakulteta, Oddelek za gozdarstvo in obnovljive gozdne vire Večna pot 83, 1000 Ljubljana; ${ }^{2 Z a v o d}$ za gozdove Slovenije, OE Sežana, Partizanska cesta 49, 6210 Sežana

*maja.jurc@bf.uni-lj.si

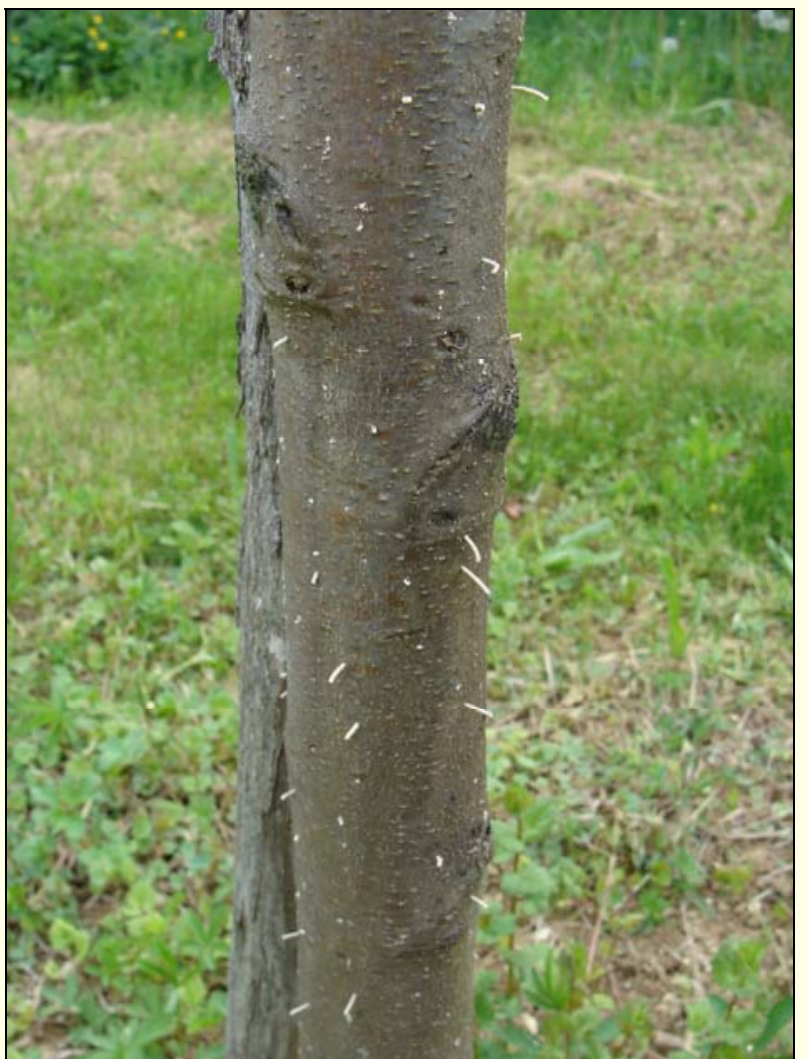

Slika 2: Aprila 2010 so se pojavili znaki napada ambrozijskega podlubnika (Xylosandrus germanus), ki je prizadel vse sorte evrojaponskega kostanja (Foto: M. Reščič)

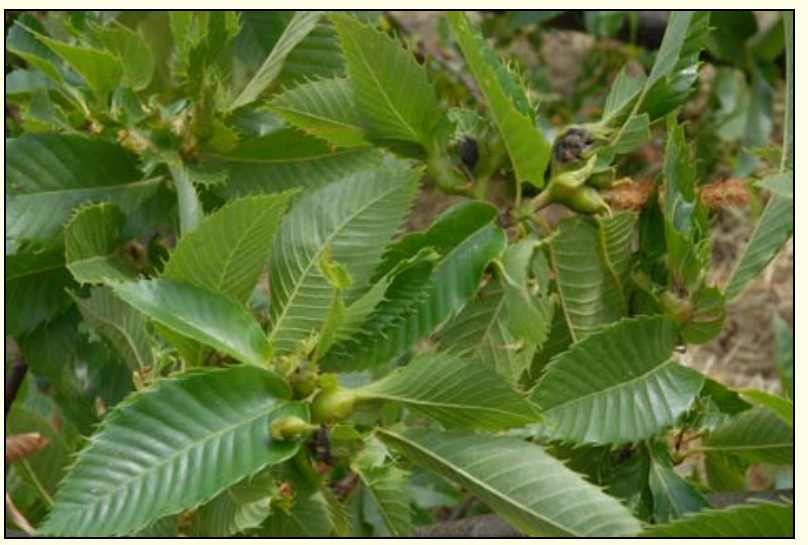

Slika 4: Novejše raziskave potrjujejo, da kostanjeva šiškarica omogoča okužbo s kostanjevim rakom (vidne so nekroze, ki jih povzroča kostanjev rak na šiškah kostanjeve šiškarice), slikano v bližini Sabotina, 29.6.2007 (Foto: M. Jurc) 